\title{
Current research in bilingualism and its implications for Cognitive Translation and Interpreting Studies
}

\author{
John W. Schwieter \\ Wilfrid Laurier University, Canada \\ jschwieter@wlu.ca \\ https://orcid.org/0000-0003-1798-3915 \\ Julia Festman \\ Pedagogical University Tyrol, Austria \\ julia.festman@ph-tirol.ac.at \\ https://orcid.org/0000-0003-0156-3713 \\ Aline Ferreira \\ University of California, Santa Barbara, United States \\ aferreira@spanport.ucsb.edu \\ https://orcid.org/0000-0002-2906-7343
}

\begin{abstract}
This article discusses research in the field of bilingualism that has the potential to inform the related, albeit disconnected, field of Cognitive Translation and Interpreting Studies (CTIS). It reviews issues such as lexical access and the multilingual mental lexicon, inhibitory control and the "bilingual advantage debate". This debate refers to the question whether bilingualism leads to cognitive advantages that monolinguals do not develop. Although these claims have not been fully tested in translators and interpreters - both novice and advanced professionals - it is plausible that if there are indeed cognitive advantages that arise from managing "two languages in one mind", such benefits may correlate with neural and cognitive changes due to the training, accumulated experience and expertise of translators and interpreters. These topics merit inclusion in the expanding set of prominent research themes in CTIS. Future research in CTIS can use findings from bilingualism and the bilingual advantage debate to account for the peculiarities of translational cognition.
\end{abstract}

Keywords: bilingualism; bilingual advantage; bilingual lexical access; inhibitory control; executive functioning 
Schwieter, J. W., Festman, J., \& Ferreira, A. (2020). Current research in bilingualism and its implications for Cognitive Translation and Interpreting Studies. Linguistica Antverpiensia, New Series: Themes in Translation Studies, 19, 80-93.

\section{Introduction}

As a field of enquiry, bilingualism is informed by a variety of disciplines, including linguistics, sociology, psychology, education and anthropology. At these many intersections is the growing body of research which investigates the cognitive and neuroscientific aspects of bilingualism. Scholars interested in this line of work seek to answer questions such as:

- How do human beings acquire and comprehend multiple languages, and how do they produce utterances in them?

- What are the cognitive consequences of being bilingual?

- How are multiple languages represented in one mind?

- How does bilingualism change language processing and human cognition in general?

- How is the bilingual brain different from the monolingual brain?

Handbook-length projects over the past 20 years or so are both testament to this rapid growth and recognition of cognitive approaches to bilingualism as a sub-field within bilingualism (de Groot \& Kroll, 1997; Kroll \& de Groot, 2005; Schwieter, 2015, 2019; De Houwer \& Ortega, 2018). At the same time as this expansion occurred, another related sub-field emerged in a neighbouring discipline. Cognitive Translation and Interpreting Studies (CTIS) is also a relatively new area of research in the field of Translation Studies that has now been the topic of several volumes (Alves, 2003; Ferreira \& Schwieter, 2015; Muñoz, 2016; O'Brien, 2011; Rojo \& Ibarretxe, 2013; Schwieter \& Ferreira, 2014, 2017b; Shreve \& Angelone, 2010) and, most recently, the rationale behind launching a new international peer-reviewed journal Translation, Cognition \& Behavior (2018).

The relevance of bilingualism to CTIS and vice versa is clear, and the potential for both areas to inform each other is all but certain. However, the dialogue between the two has been scant to say the least, with few papers calling for researchers to find ways to bridge these complementary sub-fields (see Schwieter \& Ferreira, 2017a). In this article, ongoing work in bilingualism is discussed that has the potential to inform theoretical models in CTIS. In the following sections, we provide an overview of current research in bilingualism, beginning with the consideration that the bilingual mental lexicon, rather than the monolingual lexicon, can be thought of as the "default". We then consider how more than one language is controlled and regulated in the mind. Following this, we reflect on the bilingual advantage debate and review the limited amount of work among novice and professional translators and interpreters. This debate holds that bilingualism may lead to cognitive benefits such as enhanced executive functions due to the constant management and use of two languages (Bialystok, 2017). Although we do not take a specific stand in this sometimes heated discussion, we review results that both support and refute any bilingual advantage over monolingualism and discuss how these findings have theoretical implications for CTIS. We conclude by offering some empirical suggestions and theoretical implications that researchers in CTIS may wish to consider when moving forward. 
Schwieter, J. W., Festman, J., \& Ferreira, A. (2020). Current research in bilingualism and its implications for Cognitive Translation and Interpreting Studies. Linguistica Antverpiensia, New Series: Themes in Translation Studies, 19, 80-93.

\section{Relevant research in the field of bilingualism}

\subsection{The bilingual mental lexicon}

We start our discussion by describing the mental lexicon as the "dictionary in the mind" that contains information about words' meanings, pronunciation and syntax, among other characteristics. Scholars interested in the mental lexicon examine the ways in which words are stored, activated, retrieved and processed. Given that we are constantly learning new words throughout life, our mental lexicon is continuously and dynamically changing. This is particularly true in the case of bilingualism, where the mental lexicon consists of words in two languages. Accordingly, integrating the representation of two languages in one mental lexicon has been an expansive area of research in the past ten years or so.

One of the main research questions related to the bilingual mental lexicon has to do with the extent to which there is either non-selective or selective access to the lexicon and whether words in both languages are activated in parallel or selectively. Selective access to the lexicon holds that only one language system is activated at any given time as needed by the context. However, the non-selective line of thought argues that there is a single, integrated lexicon with information pertaining to the individual's languages that is activated in parallel. Whereas there has been empirical support for non-selective and selective access to the bilingual mental lexicon, we are seeing more and more that bilingual language processing in general is more non-selective than originally thought (Libben, 2017).

A number of models have depicted the way in which the bilingual mental lexicon is organized and accessed. Many of these account for evidence supporting non-selective or selective activation in the bilingual mental lexicon. Perhaps among the most cited of these hypotheses is the notion of language mode (Grosjean, 2001) and the interactive activation that is characteristic of processing two languages (Dijkstra \& Van Heuven, 2002). Grosjean's language mode theory suggests that bilinguals decide, usually unconsciously, which language to use and how much of the other language not to use depending on several psychosocial and linguistic factors. In turn, this allows bilinguals to place themselves in a state which spans a spectrum from monolingual mode (i.e., activation is predominately in one language) to bilingual mode (i.e., activation is equal, or nearly equal, in both languages). Some research projects have shown that changes in language mode can influence language processing in bilinguals (Dunn \& Fox Tree, 2014); and calls have recently been made for research to examine how experience with language modes (Yu \& Schwieter, 2018) - and the bilingual experience in general (de Bruin, 2019) - may have some explanatory power in the bilingual advantage debate which we discuss in more detail in Section 2.3.

The language mode theory is interested in the relationship between bilinguals and their environment and how this affects whether their lexical processing is either non-selective or selective. The Bilingual Interactive Activation (BIA+) Model (Dijkstra \& Van Heuven, 2002) specifically approaches lexical activation through a connectionist framework. This model explains how bilinguals process visual and orthographic input through an integrated lexicon system. In this integrated lexicon, lexical items contain language tags that mark them as 
Schwieter, J. W., Festman, J., \& Ferreira, A. (2020). Current research in bilingualism and its implications for Cognitive Translation and Interpreting Studies. Linguistica Antverpiensia, New Series: Themes in Translation Studies, 19, 80-93.

belonging to either the L1 or the L2. For instance, when an English-Spanish (L1-L2) bilingual is shown the word gato (cat) and is asked to translate it into English, the information must first be processed by a word identification subsystem. In other words, they must first identify the word to be translated. To do so, the model argues, the orthographic and phonological cues activate the semantic representations (i.e., the meaning) and language nodes. All of this information is then used by a task/decision subsystem to perform the duty at hand (i.e., utter the word cat).

The mental lexicon is a well-studied area in psycholinguistics but it was only recently that researchers began to entertain the idea that a "multilingual mental lexicon" may be the default rather than the exception to a monolingual mental lexicon (Libben, 2017; Libben \& Schwieter, 2019; Vaid \& Meuter, 2017). In other words, studying the mental lexicon should begin with the understanding that it is equipped with the ability to represent and process words in more than one language. Libben (2017) states:

The majority of the global population functions in a multilingual context where the integration of these moderating factors is part of the normal language function. Therefore, it would seem counterintuitive to adhere to the traditional approach that monolingualism represents the default state of the mental lexicon when a bilingual default approach is able to account for a broader range of linguistic variables and interactions. (p. 119)

Of particular importance for our purposes here is to discuss the effects that the constant management of a bilingual (or multilingual) mental lexicon may have. In the next section, we first explain how bilinguals manage two languages in one mind and then we review research reporting on the cognitive consequences that this may have.

\subsection{Language regulation and control}

There is no doubt that a bilingual must have the opportunity to adapt language use to specific requirements at any point in time; on some occasions, both languages can be used freely and dense codeswitching is considered appropriate, whereas in other situations different languages are used in different ways (e.g., when translating from one language to the other) or only one language is to be used (e.g., when writing an essay in the L1 or an L2). The assumption is that in a bilingual's mental system, two languages are available and linguistic elements in both languages are active. This allows for rapid switching between them, enabling the bilingual to translate, etc. Parallel activation has been demonstrated, even when only one of the languages is currently in use and a monolingual mode would be assumed (e.g., Dijkstra, 2005; Kroll et al., 2012).

Given that both languages are activated and available simultaneously, the constant mixing of languages or cross-linguistic intrusions must be prevented in situations of monolingual mode. An efficient internal control mechanism is thought to be responsible and controls the flow of information as a domain-general process - that is, not restricted to the verbal domain (e.g., Green \& Abutalebi, 2013). In neural terms, an entire network is responsible for controlling different aspects of language processing (Abutalebi \& Green, 2007). The same network of prefrontal cortex, anterior cingulate cortex, basal ganglia and inferior parietal lobule is 
Schwieter, J. W., Festman, J., \& Ferreira, A. (2020). Current research in bilingualism and its implications for Cognitive Translation and Interpreting Studies. Linguistica Antverpiensia, New Series: Themes in Translation Studies, 19, 80-93.

involved in the control of actions and of languages and interacts dynamically depending on the type of task and its demands.

The most influential approach to conceptualizing the manner in which multiple languages are regulated in the mind draws on earlier psychological models of control of action. Green's (1998) inhibitory control model reconceptualizes language processing by thinking about tasks such as reading aloud, naming a picture and translating from one language to another in terms of task schemas. These are either routine action sequences (for often-performed tasks) or newly created action sequences (for novel tasks). The Supervisory Attentional System (adopted from Norman \& Shallice's (1986) theory on control of behaviour) is in charge of planning, regulating and verifying task execution, and is resource-limited.

Using a specific language entails the activation of the task schema use Language $x(\mathrm{Lx})$. This task schema is executed by conceptual information in the conceptualizer according to an increase in activation of only those lemmas stored in the lexico-semantic system that are equipped with the language tag $L x$. All lemmas tagged for another language are inhibited at this stage. In addition to this proactive activation of $L x$, reactive inhibition is included for contextually inappropriate lexical elements that might be activated erroneously (what might occur owing to limitations of resources). The task schema translates words from $L x$ to Language y (Ly), according to Green's model, includes the Supervisory Attentional System performing three task schemas by specifying $L x$ as the input language, $L y$ as the output language, and $L x$ as the language which must be inhibited to produce $L y$.

Distinctions between global and local control have been put forward. Global control refers to the idea of activating all the units of a target language (TL) while inhibiting all those of the non-TL. Local control is more specific, as only certain elements in a given language are inhibited. A further distinction is made between proactive and reactive control. Consciously deciding to use a certain language might lead to the preparation of the language system of the TL and reduce a priori the availability of the non-TL. Reactive control, in contrast, is involved in later processing stages, when several language competitors are already activated and need to be selected for output. This means that interference can be detected and solved by means of reactive control. The locus of control refers to where in the language production/comprehension system control is exerted, either more on the language system itself or only on the output of the language system.

The different aspects of control indicate that it is a highly adaptive mechanism at the core of realizing the linguistic needs of a bilingual. It helps to focus on a certain language (proactive control, global control), it assists in preventing cross-language intrusions (proactive, global and, if they are not sufficiently successful, reactive local control) and, owing to its flexibility, it allows for changes in the TL, switching, translating, etc. The Adaptive Control Hypothesis (Green \& Abutalebi, 2013) points to the flexible nature of the control ability and explains how the cognitive system orchestrates its processes to achieve highest efficiency in the everchanging demands of current situations. 
Schwieter, J. W., Festman, J., \& Ferreira, A. (2020). Current research in bilingualism and its implications for Cognitive Translation and Interpreting Studies. Linguistica Antverpiensia, New Series: Themes in Translation Studies, 19, 80-93.

For such peak performance involving cascades of cognitive processes it is likely that different control processes are necessary - early and late, global and local - and that highly proficient bilinguals have also learned to make the most of the adaptive control system. Translation could then be thought of as the mastery of early global inhibition of the currently irrelevant language abilities. This means that if one translates from $L x$ to $L y$, production in $L x$ and comprehension in $L y$ are not necessary and could therefore be inhibited early on in task execution to reduce cross-language competition (and to increase processing efficiency). Crucially, cognitive control is highly affected by individual differences: some individuals demonstrate excellent cognitive control abilities whereas others struggle in this domain. A series of studies on highly proficient Russian-German students revealed that individual differences in cognitive control are clearly linked to language control ability (Festman, 2012; Festman \& Münte, 2012; Festman, Rodríguez-Fornells, \& Münte, 2010).

The language-switching task is frequently used to examine these control processes. In an experimental setup, a series of pictures is presented, the choice of the TL is usually predefined and cued - either in a random order or in a fixed order, for example, alternating between response languages. While participants name sequences of pictures and switch between their languages as required, their responses and the time to name the pictures are recorded. Typically, naming pictures in the same language for a few consecutive trials is easier (i.e., faster and more accurate) than naming a picture in a language that is different from the immediately prior trial. In a trilingual switching study, Festman and Mosca (2016) described the flexible adaptation of control processes according to task requirements. Their findings suggest that sustained proactive control mechanisms are needed when the use of only one language is required for sequences of trials, but for frequent switching, transient, perhaps more reactive control processes are necessary.

\subsection{Is a cognitive advantage incurred from bilingualism?}

At the heart of the bilingual advantage debate is the aim to determine the effects of bilingualism on cognition. Up until Peal and Lambert's (1962) seminal study, bilingualism was considered to be detrimental to a child's cognitive development. From this turning point onwards, earlier studies were criticized for their lack of methodological rigour and fairness, in particular regarding crucial background variables such as socio-economic status, age and level of education. More than 50 years later, a large number of studies has gathered empirical information on the effects of bilingualism on cognition, but the picture we have gained from this intense research activity is not yet quite clear (see recent reviews by Lehtonen et al., 2018; Van den Noort et al., 2019; and a critical view by Paap et al., 2020).

From the description of the way in which the mind regulates the constant availability of two (or more) languages in one mind, it seems appropriate to assume an additional training of the domain-general control system and that the lifelong use of two languages is likely to have an effect on the ease, speed and level of processing and performance. A large number of studies provided evidence for the existence of a bilingual advantage in that the bilingual groups (infants, children, adults, elderly people) outperformed their monolingual counterparts. Other studies, however, provided evidence for the opposite: they found no bilingual 
Schwieter, J. W., Festman, J., \& Ferreira, A. (2020). Current research in bilingualism and its implications for Cognitive Translation and Interpreting Studies. Linguistica Antverpiensia, New Series: Themes in Translation Studies, 19, 80-93.

advantage or even a disadvantage. These studies are based on many different tasks to assess cognitive performance; they include a variety of language combinations in the bilingual cohorts and differ largely in sample sizes, the inclusion of background variables and methodological rigour.

Whereas some researchers put aside the riddle of the bilingual advantage, others attempt to find ways to solve it by getting away from the yes-no dilemma the debate has led into. Czapka et al. (2019) investigate whether a possible bilingual advantage could be transferred into reallife school situations and how background variables and testing conditions modulate the findings. In addition, pairwise-matching as a new way of treating highly heterogeneous samples has been demonstrated as a path to revealing the bilingual advantage in small, wellmatched participant groups (Czapka et al., 2020).

\section{Translators and interpreters}

Significant gains have been made in our knowledge of the ways in which two or more languages are processed, represented and controlled in one mind. We have also progressed regarding the consequences this has for cognition, executive functions and ageing. Nevertheless, these research agendas have scantly begun to widen their scope to investigate how these issues play out in (professional) translators and interpreters (see Schwieter \& Ferreira, 2018 for initial discussions). This work, for explanations discussed above, has focused on simultaneous interpreters - those who are constantly juggling two languages in unique ways that other bilinguals typically do not perform.

A number of studies have shown that simultaneous interpreters have advantages in both short-term and working memory that other bilinguals do not exhibit (Babcock \& Vallesi, 2017; Bajo et al., 2000; Christoffels et al., 2006; Hiltunen, et al., 2014). Some of the early work examining these issues focused on potential working-memory enhancements as a consequence of extensive practice and/or training in simultaneous interpreting. Christoffels et al. (2006) asked whether bilingual students, professional interpreters and language teachers carry out certain language-processing events in the same way. They compared the performance of these three populations on a series of psycholinguistic tasks: picture naming; reading, speaking and word spans; and word translation. The results showed that professional interpreters outperformed bilingual students in speed and accuracy on all tasks. However, they outperformed the language teachers only on the memory span tasks, suggesting that working memory is an important sub-skill for simultaneous interpreting but that lexical access is modulated by overall language proficiency. Another important finding they reported was that, although working memory and short-term memory capacity were unaffected by the language of testing for the interpreters, the other two groups performed significantly better when tested in the L1. This implies that professional interpreters have "developed greater efficiency in language processing capacity in the L2 than ordinary bilinguals" (Christoffels et al., 2006, p. 343).

A study by Christoffels et al. (2006) was unable to explain whether the enhanced memory observed among professional interpreters is a prerequisite or a consequence of their 
Schwieter, J. W., Festman, J., \& Ferreira, A. (2020). Current research in bilingualism and its implications for Cognitive Translation and Interpreting Studies. Linguistica Antverpiensia, New Series: Themes in Translation Studies, 19, 80-93.

extensive experience with simultaneous interpreting. To this end, Babcock et al. (2017) conducted a longitudinal study among interpreting students, translation students and students majoring in unrelated areas. The participants were administered tests of short-term and working memory, the attention network task, and a task-switching experiment at the beginning and end of their programmes, which ranged from 19-24 months later.

The results of the pre-test showed no differences in memory and executive functioning between the three groups, suggesting that it may not be individual inherent differences that explain cognitive advantages for interpreters. However, at the conclusion of the study, although all the groups showed some improvement in performance, the interpreters significantly improved in verbal short-term memory performance. These findings suggest that interpreters do not possess inherent advantages in memory and executive functioning, but rather that these advantages emerge through simultaneous interpreting training and later experience to which others are not exposed (see also Dong \& Liu, 2016).

Rather than focusing on simultaneous interpreting, Dong et al. (2018) examined whether similar advantages arising from training in simultaneous interpreting could also be observed from training in consecutive interpreting. Pöchhacker (2011b) defines simultaneous interpreting as being produced in synchrony with the interpreter's perception and comprehension of the source utterance with a processing-related time lag of a few seconds between input and output. Consecutive interpreting, however, is a two-stage process in which the source-speech comprehension is followed by the re-expression in another language (Pöchhacker, 2011a). In Dong et al. (2018), Chinese learners of English were divided into two groups, one which received consecutive interpreting training and one which received general instruction in the second language (L2). Prior to and at the conclusion of the semester, the individuals participated in a non-verbal updating task, an L2 listening span task and a letter span task. 'Updating' refers to the cognitive ability to supervise behaviour and actions while carrying out any given task to ensure that the task at hand is performed correctly. Also, in the post-test, the participants were measured for consecutive interpreting performance. The results showed that updating abilities predicted consecutive interpreting performance. The consecutive interpreting training also enhanced updating compared to the group that received only language instruction.

Although there was a strong correlation between consecutive interpreting training and nonverbal updating, this relationship did not emerge between the training and performance on the other two tasks that looked at working memory spans. From a theoretical perspective, this suggests that in consecutive interpreting, unlike simultaneous interpreting, updating and the recalling process may share the same attentional control process and therefore may be more crucial than working memory.

In addition to research investigating short-term memory and working memory, interpreters seem to have advantages when orienting their attentional network (Morales et al., 2015), coordinating multiple tasks in a dual-task paradigm (Becker et al., 2016; Strobach et al., 2015) and sustaining inhibitory control in task-switching paradigms (Babcock \& Vallesi, 2017; Becker et al., 2016). The study by Yudes et al. (2011) showed that experience in interpreting has 
Schwieter, J. W., Festman, J., \& Ferreira, A. (2020). Current research in bilingualism and its implications for Cognitive Translation and Interpreting Studies. Linguistica Antverpiensia, New Series: Themes in Translation Studies, 19, 80-93.

positive consequences for executive processing. The researchers compared the performance of simultaneous interpreters, bilinguals and monolinguals on a Simon task (estimating inhibitory control) and the Wisconsin card-sorting task (estimating cognitive flexibility). The interpreters outperformed the other two groups in the Wisconsin card-sorting task, suggesting that they were able to update the task-relevant information more efficiently and to adjust their responses accordingly. However, the interpreters preformed similarly to the other two groups in the Simon task, leading the researchers to argue that being a simultaneous interpreter per se does not lead to an enhanced ability to reduce interference from conflicting information. It seems likely that not all aspects of executive processing modulate interpreting and that future research will need to investigate this further.

\section{Implications}

Some progress has been made in interfacing research in bi- or multilingualism with CTIS, with new work on the horizon (Ferreira \& Schwieter, in press). Theoretically speaking, Schwieter and Ferreira (2017) discussed the multilingual lexicon, language recoding, working memory, language selection and control processes as important issues that merit further exploration. Expertise and skill development have also been variables of interest, and they have revealed a better understanding of how translators and interpreters process languages. We believe that communication between those ongoing studies and CTIS is essential. Along with theory, empirical studies that focus on CTIS are much in need to elucidate the nuances of cognitive functioning and translation processes.

One area that merits further investigation is directionality in translation and interpreting that is, comparing the L2-L1 and L1-L2 directions. Gile (2005) states that "[o]ne of the oldest issues discussed in the translation and interpreting community is directionality" (p. 9). However, Pokorn (2005) argues that directionality is in need of rehabilitation - although using an L2 is a common social practice, translating or interpreting into one's non-native language is discouraged and the L2 product often considered to be inferior or less natural in many Western countries. Despite this, a survey conducted by the International Association of Professional Translators and Interpreters (2015) found that more than half of the 772 respondents reported primarily translating into their $L 2$. It is evident, therefore, that inverse translation is a necessary practice - one which has only recently received attention in the field (Beeby, 2009; Hagemann, 2019; Hunziker Heeb, 2016; Marmaridou, 1996; Wang, 2011; for reviews see Ferreira \& Schwieter, 2017 and Zahedi, 2013). Whereas these studies have made important first steps, we argue here that a better assessment of both process and product should not rely on a translators' native languages nor should it rely on the direction in which they are translating, but rather on their abilities, strategies and commands of the source languages (SLS) and target languages (TLS) and cultures.

The directionality of translation might be viewed in this light as a combination of solid training of language/cognitive control abilities (cf. Green, 1998) and language command. Recently, two studies have explored how bilingual competence plays a differential role in direct and inverse translation. Using eye-tracking, Ferreira et al. (2016) empirically analysed the metacognitive processes of translators and how translators' behaviour is adapted during a 
Schwieter, J. W., Festman, J., \& Ferreira, A. (2020). Current research in bilingualism and its implications for Cognitive Translation and Interpreting Studies. Linguistica Antverpiensia, New Series: Themes in Translation Studies, 19, 80-93.

translation task in which they switched between source and target texts. In another study, Ferreira et al. (2018) investigated verbal utterances that were then classified into two categories: problem identification and prospective solution. Again, there were differences between translating into the L1 versus into the L2, demonstrating that a translator's performance and behaviour are adapted depending on the task at hand (see Zheng et al., 2020 for an alternative account). Importantly, both studies included detailed information on the participants' bilingual profile, which seemingly helped with interpreting the role of bilingual competence in the directionality of translation.

Skills in both languages are one of the main factors contributing to translation performance. However, not all translators are highly or equally proficient in their translation languages. Some regularly work with two, others with more than two languages (Henrard \& van Daele, 2017). This is why it would be beneficial for future work in CTIS to describe in detail the multilingual profile and language history of participants, without assuming that translators are highly proficient or have had equal backgrounds both within and outside of their training and language experiences. Empirical research on bi- and multilinguals' language performance has already revealed the need for a closer look at their individual differences, in both the language and the cognitive domains (see Section 2.2). The studies by Festman and colleagues could be taken as a basis for arguing in favour of the crucial impact of language control and cognitive control abilities in the face of high cognitive demands such as those that accompany translation.

Future work should continue to study the ways in which working memory affects translation processes, following Christoffels et al. (2006) and Babcock et al. (2017). Longitudinal studies, such as Dong and Liu's (2016), could contribute to this dialogue, given the explanatory power they offer with respect to cognitive control effects in adults who have undergone different translation and interpreting training. In this sense, tasks that measure short- and long-term memory, attentional networks and inhibitory control should be included in CTIS study designs if we are to gain a broader view of participants' conflict-resolution profiles - something that could help us to interpret better the data collected from bilinguals with a range of competency levels. It seems that we are at a fruitful juncture where it is time for researchers in CTIS to test empirically the ways in which various bilingual experiences are linked to higher processing demands and translation performance. The bilingual advantage debate (see Section 2.3) and the dialogue on the "interpreter advantage" (García, 2014) have already set the stage for such an endeavour.

\section{References}

Abutalebi, J., \& Green, D. (2007). Bilingual language production: The neurocognition of language representation and control. Journal of Neurolinguistics, 20(3), 242-275. https://doi.org/10. 1016/i.jneuroling.2006.10.003

Alves, F. (Ed.). (2003). Triangulating translation: Perspectives in process oriented research. John Benjamins. https://doi.org/10.1075/btl.45 
Schwieter, J. W., Festman, J., \& Ferreira, A. (2020). Current research in bilingualism and its implications for Cognitive Translation and Interpreting Studies. Linguistica Antverpiensia, New Series: Themes in Translation Studies, 19, 80-93.

Babcock, L., Capizzi, M., Arbula, S., \& Vallesi, A. (2017). Short-term memory improvement after simultaneous interpretation training. Journal of Cognitive Enhancement, 1(3), 254-267. https://doi.org/10.1007/s41465-017-0011-x

Babcock, L., \& Vallesi, A. (2017). Are simultaneous interpreters expert bilinguals, unique bilinguals, or both? Bilingualism: Language and Cognition, 20(2), 403-417. https://doi.org/10. 1017/S1366728915000735

Bajo Molina, M., Padilla Adamuz, F., \& Padilla Benítez, P. (2000). Comprehension processes in simultaneous interpreting. In A. Chesterman, N. Gallardo San Salvador, \& Y. Gambier (Eds.), Translation in context (pp. 127-142). John Benjamins. https://doi.org/10.1075/btl.39.15baj

Becker, M., Schubert, T., Strobach, T., Gallinat, J., \& Kühn, S. (2016). Simultaneous interpreters vs. professional multilingual controls: Group differences in cognitive control as well as brain structure and function. Neurolmage, 134, 250-260. https://doi.org/10.1016/i.neuroimage.2016.03.079

Beeby, A. (2009). Directionality. In M. Baker \& G. Saldanha (Eds.), The Routledge encyclopedia of translation studies (pp. 84-88). Routledge.

Bialystok, E. (2017). The bilingual adaptation: How minds accommodate experience. Psychological Bulletin, 143, 233-262. https://doi.org/10.1037/bul0000099

Christoffels, I., de Groot, A. M. B., \& Kroll, J. (2006). Memory and language skills in simultaneous interpreters: The role of expertise and language proficiency. Journal of Memory and Language, 54(3), 324-345. https://doi.org/10.1016/i.jml.2005.12.004

Czapka, S., Klassert, A., \& Festman, J. (2019). Executive functions and language: Their differential influence on mono- vs. multilingual spelling in primary school. Frontiers in Psychology, 10, Article 97. https://doi.org/10.3389/fpsyg.2019.00097

Czapka, S., Wotschack, C., Klassert, A., \& Festman, J. (2020). A path to the bilingual advantage: Pairwise matching of individuals. Bilingualism: Language and Cognition, 23(2), 344-354. https://doi.org/10.1017/S1366728919000166

de Bruin, A. (2019). Not all bilinguals are the same: A call for more detailed assessments and descriptions of bilingual experiences. Behavioral Sciences, 9(3), Article 33. https://doi.org/10. $3390 /$ bs9030033

de Groot, A. M. B., \& Kroll, J. (Eds.). (1997). Tutorials in bilingualism: Psycholinguistic perspectives. Lawrence Erlbaum.

De Houwer, A., \& Ortega, L. (2018). The Cambridge handbook of bilingualism. Cambridge University Press. https://doi.org/10.1017/9781316831922

Dijkstra, T. (2005). Bilingual visual word recognition and lexical access. In J. Kroll \& A. de Groot (Eds.), Handbook of bilingualism: Psycholinguistic approaches (pp. 179-201). Oxford University Press.

Dijkstra, T., \& Van Heuven, W. (2002). The architecture of the bilingual word recognition system: From identification to decision. Bilingualism: Language and Cognition, 5(3), 175-197. https://doi.org/10.1017/S1366728902003012

Dong, Y., \& Liu, Y. (2016). Classes in translating and interpreting produce differential gains in switching and updating. Frontiers in Psychology, 7, Article 1297. https://doi.org/10.3389/fpsyg.2016.01297

Dong, Y., Liu, Y., \& Cai, R. (2018). How does consecutive interpreting training influence working memory: A longitudinal study of potential links between the two. Frontiers in Psychology, 9, Article 875. https://doi.org/10.3389/fpsyg.2018.00875

Dunn, A., \& Fox Tree, J. (2014). More on language mode. International Journal of Bilingualism, 18(6), 605-613. https://doi.org/10.1177/1367006912454509

Ferreira, A., Gottardo, A., \& Schwieter, J. W. (2018). Decision-making processes in direct and inverse translation through retrospective protocols. Translation, Cognition \& Behavior, 1(1), 98-118. https://doi.org/10.1075/tcb.00005.fer 
Schwieter, J. W., Festman, J., \& Ferreira, A. (2020). Current research in bilingualism and its implications for Cognitive Translation and Interpreting Studies. Linguistica Antverpiensia, New Series: Themes in Translation Studies, 19, 80-93.

Ferreira, A., \& Schwieter, J. W. (Eds.). (2015). Psycholinguistic and cognitive inquiries into translation and interpreting. John Benjamins. https://doi.org/10.1075/btl.115

Ferreira, A., \& Schwieter, J. W. (2017). Directionality in translation. In J. W. Schwieter \& A. Ferreira (Eds.), The handbook of translation and cognition (pp. 90-105). Wiley Blackwell. https://doi.org/10.1002/9781119241485.ch5

Ferreira, A., \& Schwieter, J. W. (Eds.). (In press). The Routledge handbook of translation, interpreting, and bilingualism. Routledge.

Ferreira, A., Schwieter, J. W., Gottardo, A., \& Jones, J. (2016). Cognitive effort in direct and inverse translation performance: Insight from eye-tracking technology. Cadernos de Tradução, 36(3), 6080. https://doi.org/10.5007/2175-7968.2016v36n3p60

Festman, J. (2012). Language control abilities of late bilinguals. Bilingualism: Language and Cognition, 15(3), 580-593. https://doi.org/10.1017/S1366728911000344

Festman, J., \& Mosca, M. (2016). Influence of preparation time on language control. In J. W. Schwieter (Ed.), Cognitive control and consequences of multilingualism (pp. 145-171). John Benjamins. https://doi.org/10.1075/bpa.2.07fes

Festman, J., \& Münte, T. (2012). Cognitive control in Russian-German bilinguals. Frontiers in Psychology, 3, Article 115. https://doi.org/10.3389/fpsyg.2012.00115

Festman, J., Rodriguez-Fornells, A., \& Münte, T. (2010). Individual differences in control of language interference in late bilinguals are mainly related to general executive abilities. Behavioral and Brain Functions, 6, Article 5. https://doi.org/10.1186/1744-9081-6-5

García, A. M. (2014). The interpreter advantage hypothesis: Preliminary data patterns and empirically motivated questions. Translation and Interpreting Studies, 9(2), 219-238. https://doi.org/10.1075/tis.9.2.04gar

Gile, D. (2005). Directionality in conference interpreting: A cognitive view. In R. Godijns \& M. Hinderdael (Eds.), Directionality in interpreting the 'retour' or the native? (pp. 9-26). Communication \& Cognition.

Green, D. W. (1998). Mental control of the bilingual lexico-semantic system. Bilingualism: Language and Cognition, 1(2), 67-81. https://doi.org/10.1017/S1366728998000133

Green, D. W., \& Abutalebi, J. (2013). Language control in bilinguals: The adaptive control hypothesis. Journal of Cognitive Psychology, 25(5), 515-530. https://doi.org/10.1080/20445911.2013.796377

Grosjean, F. (2001). The bilingual's language modes. In J. Nicol (Ed.), One mind, two languages: Bilingual language processing (pp. 1-22). Blackwell.

Hagemann, S. (2019). Directionality in translation and revision teaching: A case study of an A-B teacher working with B-A students. The Interpreter and Translator Trainer, 13(1), 86-101. https://doi.org/10.1080/1750399X.2018.1540742

Henrard, S., \& van Daele, A. (2017). Different bilingual experiences might modulate executive tasks advantages: Comparative analysis between monolinguals, translators, and interpreters. Frontiers in Psychology, 8, Article 1870. https://doi.org/10.3389/fpsyg.2017.01870

Hiltunen, S., Pääkkönen, R., Vik, G.-V., \& Krause, C. (2014). On interpreters' working memory and executive control. International Journal of Bilingualism, 20(3), 297-314. https://doi.org/10.1177/1367006914554406

Hunziker Heeb, A. (2016). Professional translators' self-concepts and directionality: Indications from translation process research. The Journal of Specialized Translation, 25, 74-88.

International Association of Professional Translators and Interpreters. (2015). Translation into a nonnative language. https://www.iapti.org/files/surveys/2/IAPTI non-native report.pdf

Kroll, J., Dussias, P., Bogulski, C., \& Valdes-Kroff, J. (2012). Juggling two languages in one mind: What bilinguals tell us about language processing and its consequences for cognition. In B. Ross (Ed.), 
Schwieter, J. W., Festman, J., \& Ferreira, A. (2020). Current research in bilingualism and its implications for Cognitive Translation and Interpreting Studies. Linguistica Antverpiensia, New Series: Themes in Translation Studies, 19, 80-93.

The psychology of learning and motivation (pp. 229-262). Academic Press. https://doi.org/10.1016/B978-0-12-394393-4.00007-8

Kroll, J., \& de Groot, A. (Eds.). (2005). Handbook of bilingualism: Psycholinguistic approaches. Oxford University Press.

Lehtonen, M., Soveri, A., Laine, A., Järvenpää, J., de Bruin, A., \& Antfolk, J. (2018). Is bilingualism associated with enhanced executive functioning in adults?: A meta-analytic review. Psychological Bulletin, 144(4), 394-425. https://doi.org/10.1037/bul0000142

Libben, M. (2017). Non-selective language activation and bilingualism as the default mental lexicon. In M. Libben, M. Goral, \& G. Libben (Eds.), Bilingualism: A framework for understanding the mental lexicon (pp. 103-122). John Benjamins. https://doi.org/10.1075/bpa.6.05lib

Libben, G., \& Schwieter, J. W. (2019). Lexical organization and reorganization in the multilingual mind. In J. W. Schwieter \& M. Paradis (Eds.), The handbook of the neuroscience of multilingualism (pp. 297-312). Wiley Blackwell. https://doi.org/10.1002/9781119387725.ch14

Marmaridou, A. S. S. (1996). Directionality in translation processes and practices. Target, 8(1), 49-73. https://doi.org/10.1075/target.8.1.04mar

Morales, J., Padilla, F., Gómez-Ariza, C., \& Bajo, M. (2015). Simultaneous interpretation selectively influences working memory and attentional networks. Acta Psychologica, 155, 82-91. https://doi.org/10.1016/j.actpsy.2014.12.004

Muñoz Martín, R. (Ed.). (2016). Reembedding translation process research. John Benjamins. https://doi.org/10.1075/btl.128

Norman, D., \& Shallice, T. (1986). Attention to action: Willed and automatic control of behavior. In R. J. Davidson, G. E. Schwartz, \& D. Shapiro (Eds.), Consciousness and self-regulation (Vol. 4, pp. 118). Springer. https://doi.org/10.1007/978-1-4757-0629-1 1

O'Brien, S. (Ed.). (2011). Cognitive explorations of translation. Continuum International Publishing Group.

Paap, K. (2019). The bilingual advantage debate: Quantity and quality of evidence. In J. W. Schwieter \& M. Paradis (Eds.), The Handbook of the neuroscience of multilingualism (pp. 701-735). Wiley Blackwell. https://doi.org/10.1002/9781119387725.ch34

Paap, K., Mason, L., Zimiga, B., Ayala-Silva, Y., \& Frost, M. (2020). The alchemy of confirmation bias transmutes expectations into bilingual advantages: A tale of two new meta-analyses. Quarterly Journal of Experimental Psychology, 73(8), 1290-1299. https://doi.org/10.1177/ 1747021819900098

Peal, E., \& Lambert, W. (1962). The relation of bilingualism to intelligence. Psychological Monographs: General and Applied, 76(27), 1-23. https://doi.org/10.1037/h0093840

Pöchhacker, F. (2011a). Consecutive interpreting. In K. Malmkjær \& K. Windle (Eds.), The Oxford handbook of translation studies (pp. 201-209). Oxford University Press.

Pöchhacker, F. (2011b). Simultaneous interpreting. In K. Malmkjær \& K. Windle (Eds.), The Oxford handbook of translation studies (pp. 189-200). Oxford University Press.

Pokorn, N. (2005). Challenging the traditional axioms: Translation into a non-mother tongue. John Benjamins. https://doi.org/10.1075/btl.62

Rojo, A., \& Ibarretxe-Antuñano, I. (2013). Cognitive linguistics and translation: Advances in some theoretical models and applications. De Gruyter Mouton. https://doi.org/10.1515/9783110302943

Schwieter, J. W. (Ed.). (2015). The Cambridge handbook of bilingual processing. Cambridge University Press. https://doi.org/10.1017/CBO9781107447257

Schwieter, J. W., \& Ferreira, A. (Eds.). (2014). The development of translation competence: Theories and methodologies from psycholinguistics and cognitive science. Cambridge Scholars Publishing. 
Schwieter, J. W., Festman, J., \& Ferreira, A. (2020). Current research in bilingualism and its implications for Cognitive Translation and Interpreting Studies. Linguistica Antverpiensia, New Series: Themes in Translation Studies, 19, 80-93.

Schwieter, J. W., \& Ferreira, A. (2017a). Bilingualism in cognitive translation and interpreting studies. In J. W. Schwieter \& A. Ferreira (Eds.), The handbook of translation and cognition (pp. 144-164). Wiley Blackwell. https://doi.org/10.1002/9781119241485.ch8

Schwieter, J. W., \& Ferreira, A. (Eds.). (2017b). The handbook of translation and cognition. Wiley Blackwell. https://doi.org/10.1002/9781119241485

Schwieter, J. W., \& Ferreira, A. (2018). Bilingualism, translation, and interpreting. In K. Malmkjær (Ed.), The Routledge handbook of translation studies and linguistics (pp. 251-266). Routledge. https://doi.org/10.4324/9781315692845-17

Schwieter, J. W., \& Paradis, M. (Eds.). (2019). The handbook of the neuroscience of multilingualism. Wiley Blackwell. https://doi.org/10.1002/9781119387725

Shreve, G., \& Angelone, E. (Eds.). (2010). Translation and cognition. John Benjamins. https://doi. org/10.1075/ata.xv

Strobach, T., Becker, M., Schubert, T., \& Kühn, S. (2015). Better dual-task processing in simultaneous interpreters. Frontiers in Psychology, 6, Article 1590. https://doi.org/10.3389/fpsyg.2015.01590

Vaid, J., \& Meuter, R. (2017). Languages without borders: Reframing the study of the bilingual mental lexicon. In M. Libben, M. Goral, \& G. Libben (Eds.), Bilingualism: A framework for understanding the mental lexicon (pp. 8-39). John Benjamins. https://doi.org/10.1075/bpa.6.01vai

van den Noort, M., Vermeire, K., Bosch, P., Staudte, H., Krajenbrink, T., Jaswetz, L., Struys, E., Yeo, S., Barisch, P., Perriard, B., Lee, S., \& Lim, S. (2019). A systematic review on the possible relationship between bilingualism, cognitive decline, and the onset of dementia. Behavioral Sciences, 9(7), Article 81. https://doi.org/10.3390/bs9070081

Wang, B. (2011). Translation practices and the issue of directionality in China. Meta, 56(4), 896-914. https://doi.org/10.7202/1011259ar

Yu, Z., \& Schwieter, J. W. (2018). Recognizing the effects of language mode on the cognitive advantages of bilingualism. Frontiers in Psychology, 9, Article 366. https://doi.org/10.3389/ fpsyg.2018.00366

Yudes, C., Macizo, P., \& Bajo, T. (2011). The influence of expertise in simultaneous interpreting on nonverbal executive processes. Frontiers in Psychology, 2, Article 309. https://doi.org/ 10.3389/fpsyg.2011.00309

Zahedi, S. (2013). L2 translation at the periphery: A meta-analysis of current views on translation directionality. TranscUlturAl: A Journal of Translation and Cultural Studies, 5(1-2), 43-60. https://doi.org/10.21992/T9QDOX

Zheng, B., Báez, S., Su, L., Xiang, X., Weis, S., Ibáñez, A., \& García, A. M. (2020). Semantic and attentional networks in bilingual processing: fMRI connectivity signatures of translation directionality. Brain and Cognition, 143, Article 105584. https://doi.org/10.1016/j.bandc. $\underline{2020.105584}$ 